\title{
The Utilisation of Dijkstra's Algorithm to Assist Evacuation Route in Higher and Close Building
}

\author{
Nor Amalina Mohd Sabri, Abd Samad Hasan Basari, Burairah Husin and \\ Khyrina Airin Fariza Abu Samah \\ Center for Advanced Computing Technology (C-ACT), Faculty of Information and Communication Technology, Universiti \\ Teknikal Malaysia Melaka, Malaysia
}

Article history

Received: 09-05-2014

Revised: 09-05-2014

Accepted: 08-09-2014

Corresponding Author: Nor Amalina Mohd Sabri Center for Advanced Computing Technology (C-ACT), Faculty of Information and Communication Technology, Universiti Teknikal Malaysia Melaka, Malaysia Email: noramalinamohdsabri@gmail.com

\section{Introduction}

A disaster is an unexpected occurrence that happens anytime and anywhere. Most people are unaware about the prevention or safety awareness to face the disaster. When it happens, the evacuation process is conducted to save the victim and if there are no proper plans, the situation becomes worse. Evacuation means rapid removal of people temporarily from building or disaster in a threatened area as rescue or precautionary measure. The complex building and human behavior during the evacuation process are directly affecting the successfulness of evacuation in order to find the best evacuation routes. The best evacuation route is considered by the time consuming and the safety of the evacuee. Hence, finding the shortest path in a safest way is very important (Bu and Fang, 2010).

There are two main problems that involve in the evacuation preparedness. The first problem is evacuees find difficulties to find the best routes (Fariza et al., 2013) and secondly, their behavior makes the process more difficult. These problems occur due to the complex man made building and evacuee unfamiliar with the building structure layout. The other reason why the evacuee hard to find the best evacuation route is because the modern building currently tend to be large scale, multifunctional and complex as reported by (Wang et al., 2011). Nowadays, people chasing to build unique and complex building to compete with the others, however the smoothness of the emergency route are not take part in the first requirement. Building layout strongly influences the finding of shortest paths. The more complex of the building will increase the difficulties of evacuee to the exit route. Subsequently, evacuee will panic and show various behaviors in order to save themselves.

Decision making during an emergency situation has to be made in perfect timing in order to reduce the 
evacuation time and avoid any injuries related to the ongoing hazard. Making the best decision during the evacuation is very difficult for the evacuees, most of the times they do not know which is the best route they should choose to reach the exit especially in a building since they are unfamiliar with the building structure. Moreover, the building structure change due to the spreading of presence hazard and the task of finding a safe route is more difficult (Filippoupolitis and Gelenbe, 2009). In order to find an exit route in exact time, cooperation from the evacuee are the key factors in making the evacuation process going smoothly. As said by ( $\mathrm{Fu}$ et al., 2013) the compliance from the evacuee give the large impact on the successfulness of evacuation process. If the evacuees did not give any cooperation during the evacuation process, unfortunately the evacuation time will be longer than expected. Moreover, as reported by (Jirasingha and Patvichaichod, 2011), factors that influencing travel time are people, evacuation path, building layout design and also distance from current to destination place. In order to manage the importance factors involved during the evacuation process, a good evacuation management should be proposed.

Hence, to overcome the problems, this research proposed two objectives which are identifying the shortest path algorithm for evacuation. Then, followed by design and develop evacuation preparedness model via shortest path algorithm on exit route selection to evacuate.

This research is expected to produce independent evacuation preparedness algorithm for exit route to help evacuee to escape from building safely. It is more reliable and faster, especially to those who are not familiar with the building. Beside, a good planning is needed to evacuate the victim from the area which is in danger to a safe area. This evacuation planning can overcome the evacuee problem in finding the best evacuation route. They just have to follow the instruction given and easily find the exit route (Garg, 2011).

The important contribution is assisting the crowd of evacuee smoothly during the evacuation to find the exit and safe route in the short time. Indirectly reduce the number of victims involved in the incident.

\section{Methodology}

Figure 1 shows the research methodology approach in solving the discussed problem.

There are three steps for obtaining the shortest path in this research area. The first step to take in action is structure the layout plan of the selected building. The building that is chosen for the first real design due based on the suitability of the building research scope. The layout is focused on the higher floor for example, $14^{\text {th }}$ floor, which the office located. The reason why to choose office environment is because of their complex arrangement with too many rooms and staffs. This situation is important to be considered in finding the shortest path and manage the evacuee behavior.

Floor layout given as shown in Fig. 2 is an image format layout and has to convert into 2D blueprint layout to make it easy in generating the node and weight from node to node.2D blueprint layout was designed using Auto CAD Software exactly with the real building. The 2D blueprint layout will be added some nodes and weight. Nodes in the layout are defined by doors of the office arrangement and weight is the distance among nodes. After setting the node to all doors, egress and staircase the weight are generated from one node to another with consideration of the environment obstacle such as wall which is cannot be passing through.

Doors are selected to act as a node because it is the vital way that evacuee will choose during the evacuation in rescuing themselves to safest place. Nevertheless, because the building is on the 14th floor, window are not selected to be a node and do not have any important role. The pointed node is the staircase as it become the last egress route to get out from the building safely.

Second step relates to Visibility Graph. From the created 2D blueprint of the building, edges weight or distance from each node are accumulate into a table using excel file. This table will be read as matrix format as an easy way to plot the visibility graph. The visibility graph is plotted based on the weight of each node and the relationship of the node as shown in Fig. 3. Node relationship is defined by the direction of node either in two ways of one way. To generate the visibility graph, MATLAB program is created. Data from the excel file is imported into the MATLAB program where the data is read in matrix data format and converted into sparse array to plot the visibility graph.

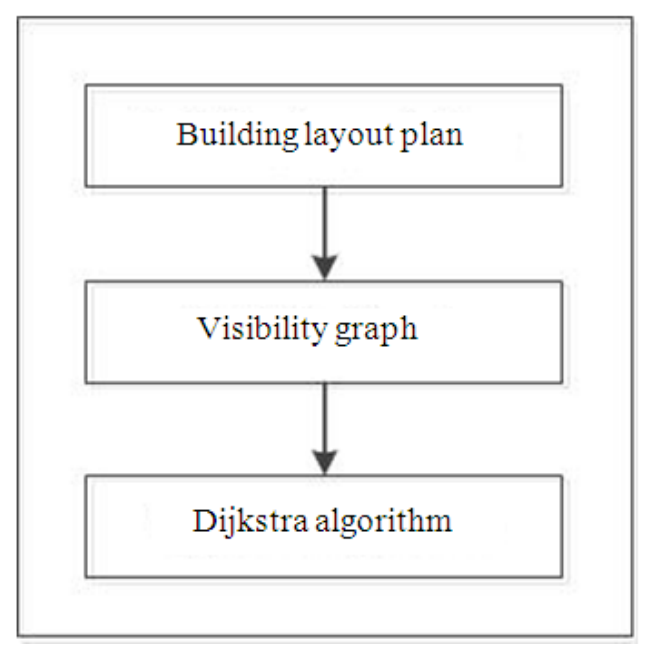

Fig. 1. Research methodology to find shortest path 


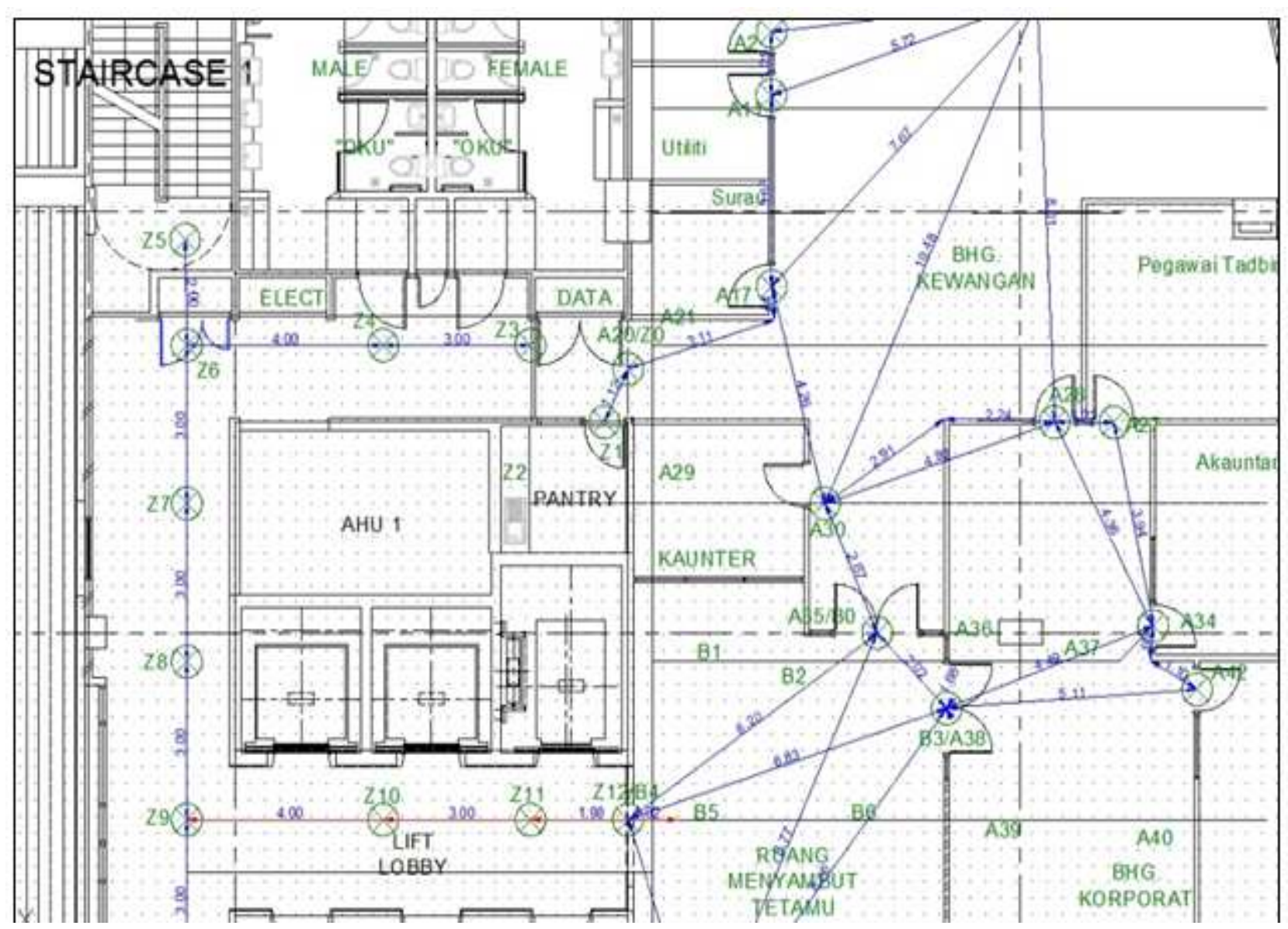

Fig. 2. 2D layout of the 14th floor office building

According to the matrix and sparse array, the MATLAB program successfully generates the visibility graph. It shows all the nodes created in the previous $2 \mathrm{D}$ blueprint layout and the relationship of the node based on the weight of each node. The structure or arrangement of the visibility graph and 2D layout is looked different. However, this matter has not given any influence and also not affects the distance calculated as long as there is no false relationship between the nodes.

Last but not least is the Dijkstra Algorithm implementation. Dijkstra Algorithm has been embedded in the MATLAB program to calculate the shortest path between nodes. A simulation has been made to calculate the distance between source node and destination node in the building. Source node is the current place of the evacuee in the building, where the destination node is the safe place or exit route to evacuate.

Dijkstra Algorithm is selected because it can calculate the shortest path efficiently in solving selection of route and provide safer evacuation plan as stated by (Kang et al., 2013) and supported by (Wang et al., 2011; Zhang et al., 2010). In addition, (Xu et al., 2012) mention that Dijkstra Algorithm targets to is to find the shortest distance between a node to all other nodes, follows by (Kaitao et al., 2012) which is nearly to scope of research. Wu and Chen (2012) Dijkstra Algorithm also claims to be the best approaches in solving simple shortest path problem and always get the shortest route from any evacuation node, same with (Lämmel et al., 2010). Furthermore, Dijkstra Algorithm is agreed $(\mathrm{Bu}$ and Fang, 2010) to be graph search algorithm which can solve the single sources shortest path problem in graph and later on supported by (Jaiswal and Chakrawarti, 2013; Biswas et al., 2013).

\section{Results}

The calculation of shortest path using Dijkstra Algorithm will generate the shortest route in the graph by displaying the different color of node. 


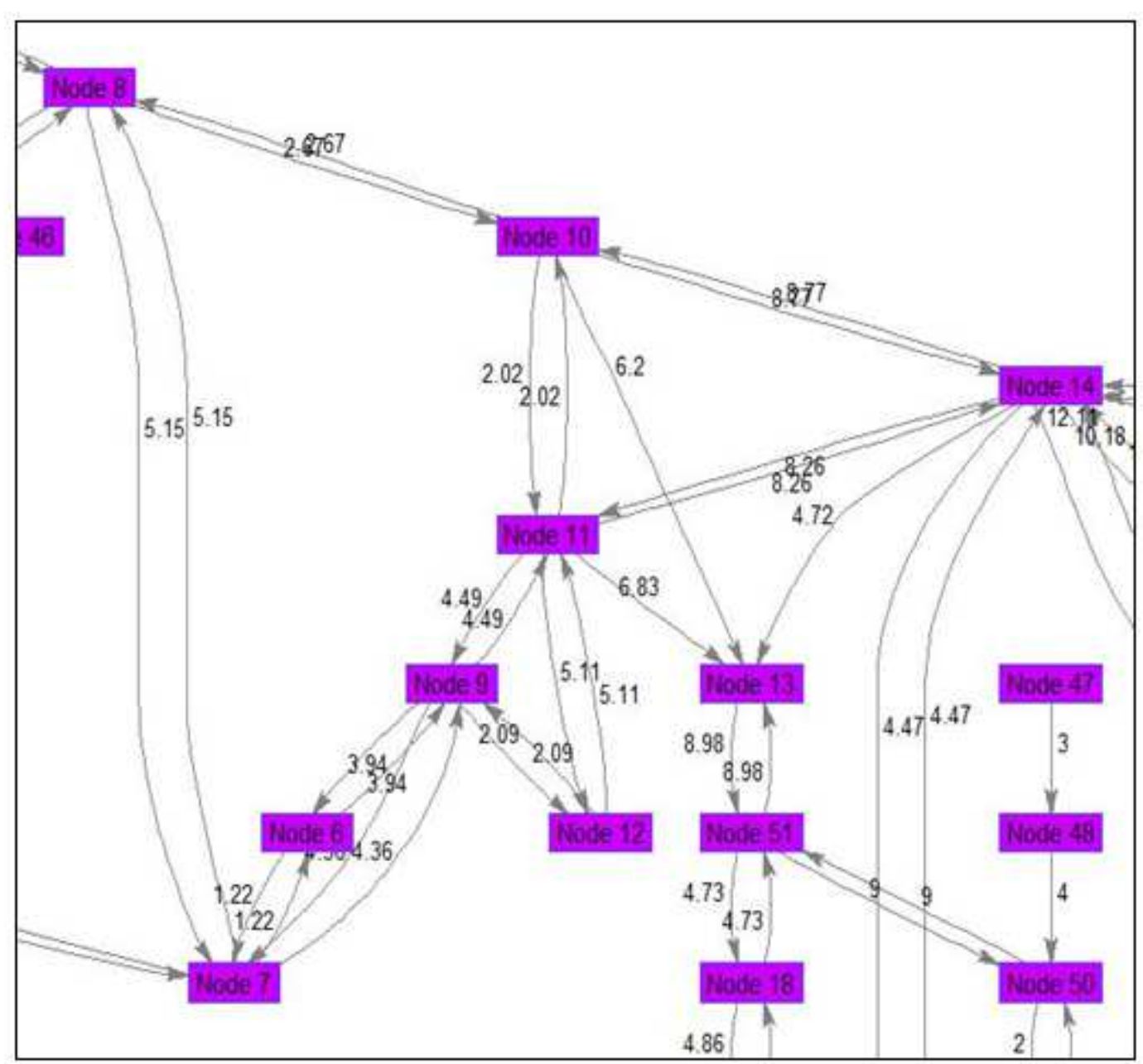

Fig. 3. Visibility graph

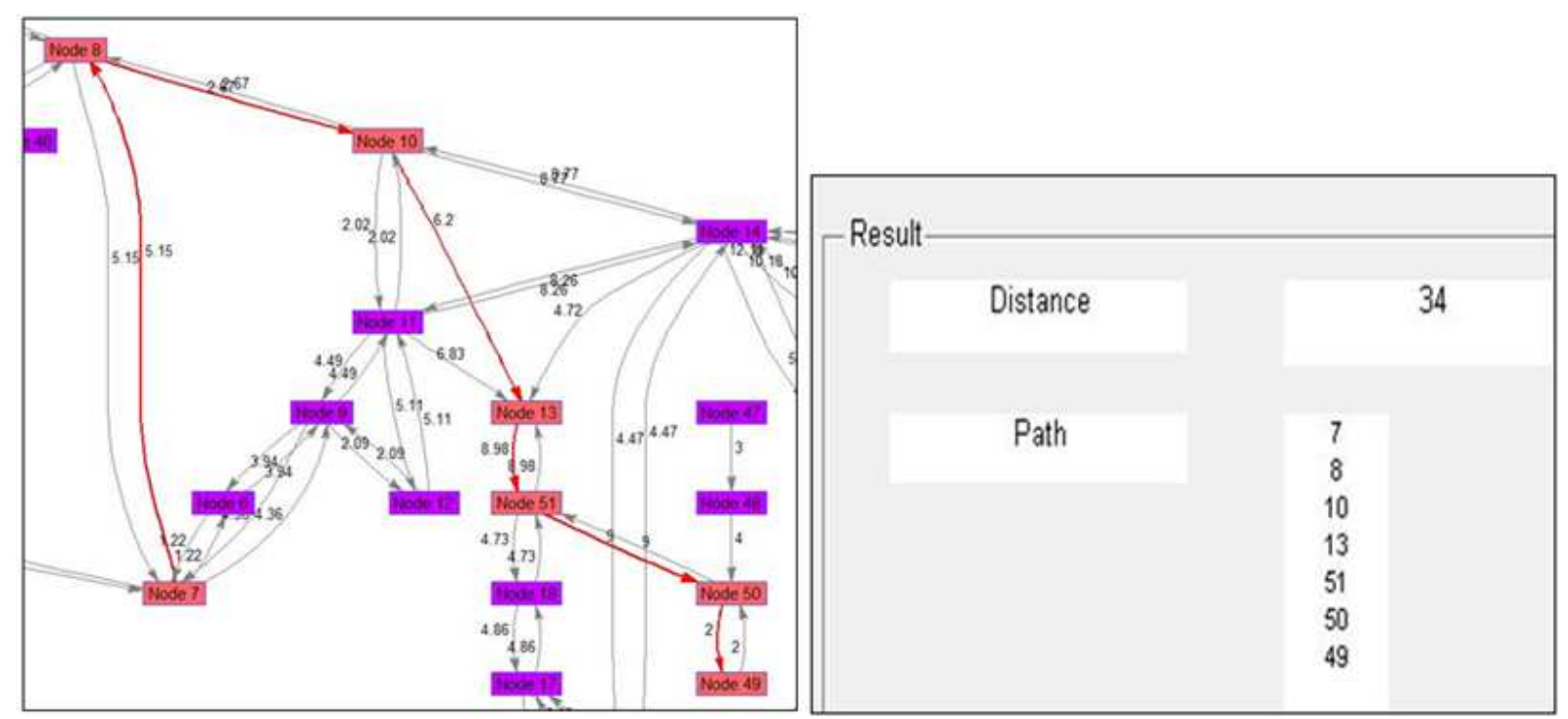

Fig. 4. Shortest path simulation result 
Total distance of the route and a list of visited path are also presented. Figure 4 shows the preliminary simulation result of the shortest path evacuation in the 14th floor building office.

The shortest path from Node 7 to Node 49 has been calculated. Dijkstra Algorithm has obtained the result, where the distance between Node 7 to Node 49 is 34 meters. This result conforms with the Dijkstra Algorithm where if there are changing of nodes, the process will repeat again until satisfy the shortest path.

\section{Discussion}

In order to calculate the best shortest path in the simulation MATLAB program, the source ID and destination ID must be given before the calculation part take place. Dijkstra Algorithm has calculated the shortest path starting from source ID to Destination ID. Based on the result, seven nodes were visited to reach the destination node which are node $7>8>10>13>51>50>49$ (Table 1 ).

As it compared to the real structure of building, the real node are renamed as shown in Fig. 5 in the visibility graph according to the matrix data and Table 2 differentiate the list of node.
As shown in Table 2, A28 which is Node 7 is a room and Node 49 represent Z5 is a staircase. Staircase is an exit route as it will guide evacuee to take the route out of the building.

Table 1. List of distance between nodes

\begin{tabular}{lc}
\hline Node & Weight \\
\hline$(7-8)$ & 5.15 \\
$(8-10)$ & 2.67 \\
$(10-13)$ & 6.20 \\
$(13-51)$ & 8.98 \\
$(51-50)$ & 9.00 \\
$(50-49)$ & 2.00 \\
Total & 34.00 \\
\hline
\end{tabular}

Table 2. Comparison of real nodes and visibility graph

\begin{tabular}{lc}
\hline Real node & Matric node \\
\hline A28 & 7 \\
A30/B0 & 8 \\
A35 & 10 \\
B4/Z12 & 13 \\
Z9 & 51 \\
Z6 & 50 \\
Z5 & 49 \\
\hline
\end{tabular}

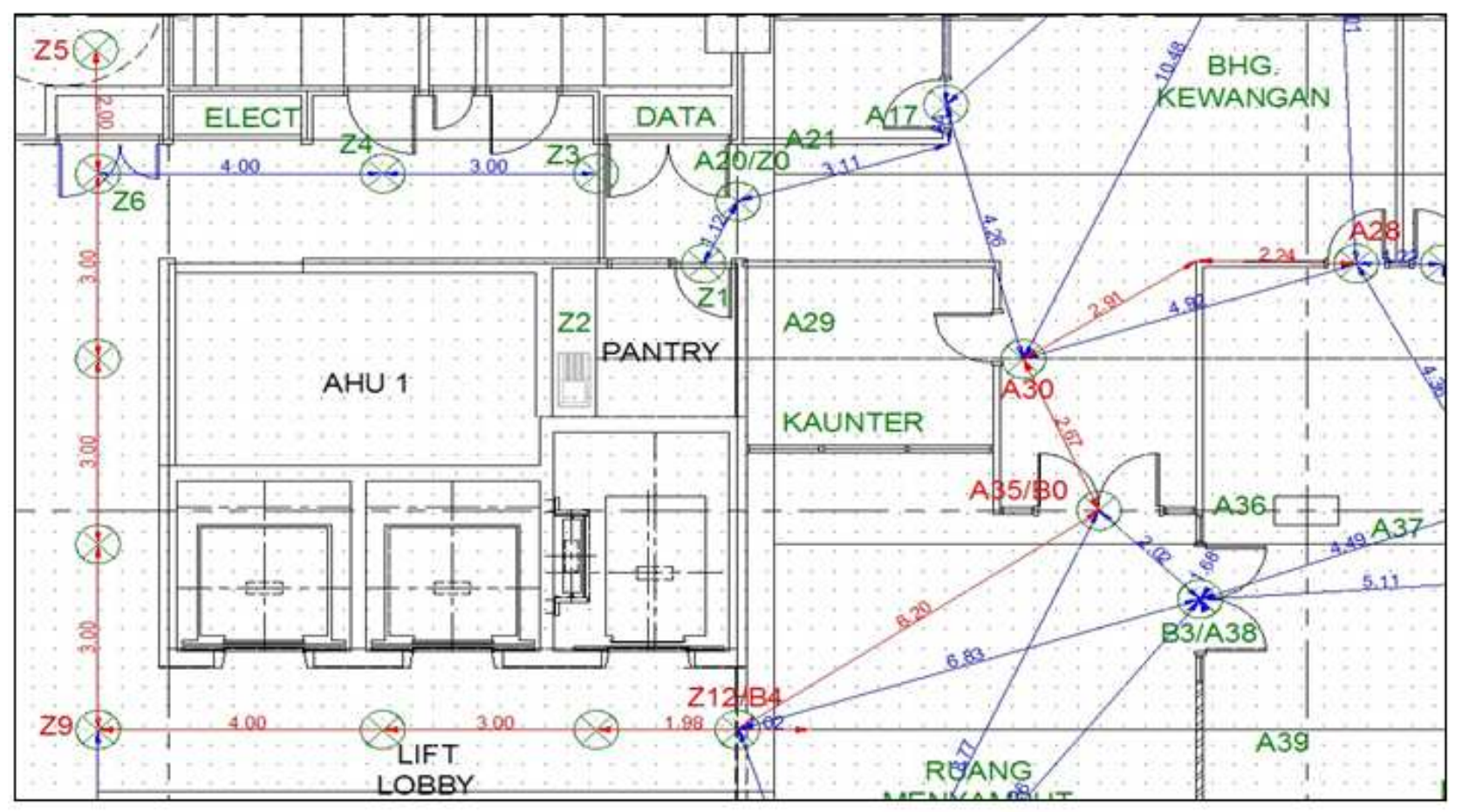

Fig. 5. Visibility graph 


\section{Conclusion}

In this study, shortest path in the selected building for 14th floor has been obtained using a MATLAB simulation program. Generating the result involve three main steps which are2D Building Layout Plan, Visibility Graph and Dijkstra Algorithm. The first step is converting the real layout plan into blueprint layout using AutoCAD software. Second step is creating the visibility graph according to matrix data of the building and the last step is finding the shortest path using Dijkstra Algorithm. The shortest path result is believed can assist evacuee to choose a suitable exit route to evacuate. For future improvements, one of the aims is to find the shortest path dynamically by considering the existence of obstacle during the evacuation process. This might involve the shortest and safest route during evacuation. The needs to enhance the Dijkstra Algorithm by utilising Artificial Intelligence (AI) method such as Ant Colony Optimization (ACO) and Particle Swarm Optimization (PSO) will be also considered.

\section{Acknowledgement}

The authors would like to thank the Faculty of Information Technology and Communication (FTMK), Universiti Teknikal Malaysia Melaka (UTeM) for supporting this research. This research also part of Master by research in Information and Communication Technology and funded under Fundamental Research Grant Scheme (FRGS) number FRGS/1/2013/ICT07/02/2/F00162.

\section{Author's Contributions}

All authors equally contributed in this work.

\section{Ethics}

This article is original and contains unpublished material. The corresponding author confirms that all of the other authors have read and approved the manuscript and no ethical issues involved.

\section{References}

Biswas, S.S., B. Alam and M.N. Doja, 2013. Generalization of dijkstra â TMS algorithm for extraction of shortest paths in directed multigraphs. J. Comput. Sci., 9: 377382. DOI: $10.3844 /$ jessp.2013.377.382

$\mathrm{Bu}, \mathrm{F}$. and H. Fang, 2010. Shortest path algorithm within dynamic restricted searching area in city emergency rescue. Proceedings of the IEEE International Conference on Emergency Management and Management Sciences, Aug. 810, IEEE Xplore Press, Beijing, pp: 371-374. DOI: 10.1109/ICEMMS.2010.5563425
Fariza, A.A.S., H. Burairah, A. Samad and H. Basari, 2013. A Systems Thinking in Natural Disaster Management: Evacuation Preparedness. 1st Edn., Advances in Economics, Risk Management, Political and Law Science, ISBN: 978-1-61804-123-4, pp: 384-389.

Filippoupolitis, A. and E. Gelenbe, 2009. A distributed decision support system for building evacuation. Proceedings of the 2 nd Conference on Human System Interactions, May 21-23, IEEE Xplore Press, Catania, pp: 323-330. DOI: 10.1109/HSI.2009.5091000

Fu, H., A.J. Pel and S.P. Hoogendoorn, 2013. Optimal traffic management to ensure emergency evacuation compliance. Proceedings of the 10th IEEE International Conference on Networking, Sensing and Control, Apr. 10-12, IEEE Xplore Press, Evry, pp: 532-537. DOI: 10.1109/ICNSC.2013.6548795

Garg, P., 2011. Modeling of evacuation planning of buildings using dynamic exits. Department of Computer Science and Engineering Indian Institute of Technology, Bombay.

Jaiswal, N. and R.K. Chakrawarti, 2013. Increasing no. of nodes for Dijkstra algorithm without degrading the performance. Int. J. Eng. Comput. Sci., 2: 569-573.

Jirasingha, W. and S. Patvichaichod, 2011. Modeling fire evacuation of a library building based on the numerical simulation. Am. J. Applied Sci., 8: 452458. DOI: 10.ajassp.2011.452.458.pdf

Kaitao, C., G. Quanbo and D. Shenan, 2012. Research and design for emergency evacuation instructions system based on wireless sensor network. Proceedings of the 24th Chinese Control and Decision Conference, May 23-25, IEEE Xplore Press, Taiyuan, pp: 3849-3854. DOI: 10.1109/CCDC.2012.6244616

Kang, W., F. Zhu, Y. Lv and G. Xiong, 2013. A heuristic implementation of emergency traffic evacuation in urban areas. Proceedings of the IEEE International Conference on Service Operations and Logistics and Informatics, Jul. 2830, IEEE Xplore Press, Dongguan, pp: 40-44. DOI: 10.1109/SOLI.2013.6611378

Lämmel, G., D. Grether and K. Nagel, 2010. The representation and implementation of time-dependent inundation in large-scale microscopic evacuation simulations. Transportat. Res. Part C: Emerg. Technol., 18: 84-98. DOI: 10.1016/j.trc.2009.04.020

Wang, T.Y., H. Rui, L. Lei and X. Wen-guo, 2011. The application of the shortest path algorithm in the evacuation system. Proceedings of the International Conference on Information Technology, Computer Engineering and Management Sciences, Sept. 24-25, IEEE Xplore Press, Nanjing, Jiangsu, 250-253. DOI: 10.1109/ICM.2011.119 
Wu, C.H. and L.C. Chen, 2012. 3D spatial information for fire-fighting search and rescue route analysis within buildings. Fire Safety J., 48: 21-29. DOI: 10.1016/j.firesaf.2011.12.006

$\mathrm{Xu}$, Y., Z. Wang, Q. Zheng and Z. Han, 2012. The application of Dijkstra's algorithm in the intelligent fire evacuation system. Proceedings of the 4th International Conference on Intelligent HumanMachine Systems and Cybernetics, Aug. 26-27, IEEE Xplore Press, Nanchang, Jiangxi, pp: 3-6. DOI: 10.1109/IHMSC.2012.7
Zhang, H., H. Liu, H. Zhang and J. Wang, 2010. Modeling of evacuations to no-notice event by public transit system. Proceedings of the 13th International IEEE Conference on Intelligent Transportation Systems, Sept. 19-22, IEEE Xplore Press, Funchal, pp: 480-484.

DOI: $10.1109 /$ ITSC.2010.5625048 